\title{
Downregulation of Endothelial Transient Receptor Potential Vanilloid Type 4 Channel Underlines Impaired Endothelial Nitric Oxide- Mediated Relaxation in the Mesenteric Arteries of Hypertensive Rats
}

\author{
A. BOUDAKA ${ }^{1 *}$, M. AL-SULEIMANI ${ }^{1 *}$, I. AL-LAWATI ${ }^{1}$, H. BAOMAR $^{1}$, S. AL-SIYABI ${ }^{1}$, \\ F. ZADJALI ${ }^{2}$ \\ *These authors contributed equally to this work.
}

${ }^{1}$ Department of Physiology, and ${ }^{2}$ Department of Biochemistry, College of Medicine and Health

Sciences, Sultan Qaboos University, Muscat, Sultanate of Oman

Received June 2, 2018

Accepted October 31, 2018

Epub Ahead of Print January 10, 2019

\section{Summary}

The endothelium contributes to the maintenance of vasodilator tone by releasing endothelium-derived relaxing factors, including nitric oxide (NO). In hypertension, endothelial nitric oxide synthase (eNOS) produces less NO and could be one of the contributing factors to the increased peripheral vascular resistance. Agonist-induced $\mathrm{Ca}^{2+}$ entry is essential for the activation of eNOS. The transient receptor potential vanilloid type 4 (TRPV4) channel, a $\mathrm{Ca}^{2+}$-permeant cation channel, is expressed in the endothelial cells and involved in the regulation of vascular tone. The present study aimed to investigate the role of TRPV4 channel in endothelium-dependent NO-mediated relaxation of the resistance artery in hypertensive rats. Using a wire myograph, relaxation response to the TRPV4 activator, 4a-phorbol-12,13-didecanoate (4aPDD) was assessed in mesenteric arteries obtained from Wistar-Kyoto (WKY) and spontaneously hypertensive rats (SHRs). Compared to WKY, SHR demonstrated a significantly attenuated 4aPDD-induced endothelium-dependent NO-mediated relaxation. Immunohistochemical analysis revealed positive staining for TRPV4 in the endothelium of mesenteric artery sections in both WKY and SHR. Furthermore, TRPV4 mRNA and protein expressions in SHR were significantly lower than their expression levels in WKY rats. We conclude that 4aPDD-induced endothelium-dependent NO-mediated vasorelaxation is reduced in SHR and downergulation of TRPV4 could be one of the contributing mechanisms.

\section{Key words}

TRPV4 - Hypertension • Endothelium • Nitric oxide • Spontaneously hypertensive rats

\section{Corresponding author}

A. Boudaka, Department of Physiology, College of Medicine and Health Sciences, Sultan Qaboos University, P.O. Box 35, Al-Khoud, Muscat 123, Sultanate of Oman; Fax: +968-24143514. E-mail: boudaka@squ.edu.om

\section{Introduction}

An increase in the peripheral vascular resistance is a characteristic finding of essential hypertension in humans and genetic strains of spontaneously hypertensive rats (SHRs) (Tobia et al. 1974, Thomas et al. 1990, Mayet and Hughes 2003, Hall et al. 2013). It is well established that the interplay between endothelial cells and the underlying vascular smooth muscle cells plays a crucial role in determining peripheral vascular resistance, which may increase as a result of either enhanced contractility or impaired relaxation of the vascular smooth muscle cells of the resistance arteries (Giles et al. 2012, Kang 2014).

The endothelium is a continuous monolayer of epithelial cells lining the blood vessels. The endothelial cells regulate the vascular tone by releasing a number of endothelium-derived relaxing factors, including nitric oxide (NO), endothelium-derived hyperpolarizing factor (EDHF) and prostacyclin $\left(\mathrm{PGI}_{2}\right)$, as well as through the generation of endothelium-dependent hyperpolarization (EDH) mainly via the activation of the small- and intermediate-conductance $\mathrm{Ca}^{2+}$-activated $\mathrm{K}^{+}$channels $\left(\mathrm{SK}_{\mathrm{Ca}}\right.$ and $\left.\mathrm{IK}_{\mathrm{Ca}}\right)$ located on endothelial cells. The 
generated EDHs are electrically transmitted to the adjacent vascular smooth muscle cells via the myoepithelial gap junctions (Félétou and Vanhoutte 2006, Bratz et al. 2008, Edwards et al. 2010, Goto et al. 2018, Loh et al. 2018). An increase in endothelial cytosolic calcium concentration is essential, at least in part, for the generation of these vasorelaxing factors (Loh et al. 2018). Various receptor agonists such as acetylcholine (ACh) and bradykinin, as well as mechanical stimuli (e.g., shear stress), can rapidly increase endothelial intracellular $\mathrm{Ca}^{2+}$ concentration $\left[\mathrm{Ca}^{+2}\right]_{\mathrm{i}}$ (Kaneto et al. 2010), which subsequently leads to the synthesis and release of the endothelial vasorelaxing factors (Hill et al. 2001). In endothelium, the rise of cytosolic calcium concentration enhances the formation of calcium-calmodulin complexes, which in turn will activate the calmodulin-binding domain of the endothelial nitric oxide synthase (eNOS), and causes NO production. Moreover, the increase in hemodynamic shear stress in the blood vessel will induce the phosphorylation of the eNOS and hence its activation with the resultant NO production. Subsequently, NO will diffuse into adjacent vascular smooth muscles to stimulate the activity of the components down its signaling cascade such as soluble guanylyl cyclase (sGC), cyclic guanosine monophosphate (cGMP), and protein kinase G (PKG), hence resulting in vasodilation. The production of $\mathrm{NO}$ can further stimulate the $\mathrm{Kca}$ channels and voltage-activated $\mathrm{K}^{+}$channels $(\mathrm{Kv})$ through the sGC-independent pathway (Quillon et al. 2015, Loh et al. 2018).

Several studies have reported the impairment of endothelial function in various models of hypertension (Fujii et al. 1992, Hilgers and Webb 2007, Dal-Ros et al. 2009, Giles et al. 2012). Endothelial dysfunction in hypertension has been suggested to be due to reduced activity and expression of endothelial $\mathrm{SK}_{\mathrm{Ca}}$ and $\mathrm{IK}_{\mathrm{Ca}}$ channels, which are known to be the major contributors to EDH-mediated effect (Weston et al. 2010, Seki et al. 2017) or reduced NO-dependent relaxation (Yang and Kaye 2006). eNOS was found to produce less nitric oxide in hypertensive rats than it did in cells from normotensive rats (Hayakawa and Raij 1998). This low NO production could be attributed to either uncoupling of eNOS, which shifts it from NO production to reactive oxygen species (ROS) production (Landmesser et al. 2003), or insufficient increase in the cytosolic calcium concentration that is necessary for eNOS activation (Mendoza et al. 2010, Loh et al. 2018).

Recent studies have introduced the importance of Transient Receptor Potential Vanilloid 4 (TRPV4) channels in the regulation of vascular tone by providing a potential $\mathrm{Ca}^{2+}$ entry channel in the vascular endothelial cells for the activation of vasodilator mechanisms in conduit and resistance arteries. Thus the intracellular calcium increase, mediated by TRPV4 channels, triggers both NO- and/or EDH-dependent vasodilatation, an effect that seems to be dependent on the studied vascular bed (Filosa et al. 2013, Nishijima et al. 2014). Interestingly, in several cell types including endothelial and smooth muscle cells, calcium handling proteins are located in caveolae. TRPV4 was shown to be also expressed as a heterotetramer with TRPC1 and, that alone or in complex with TRPC1, is able to interact with the structural caveolar protein caveolin-1 and this interaction is functionally important for the TRPV4-mediated calcium signaling and subsequent vasodilation (Filosa et al. 2013).

TRPV4 was initially reported as an osmo- or mechano-sensor (Liedtke et al. 2000, Strotmann et al. 2000) that can be activated by diverse chemical stimuli, including the synthetic phorbol ester $4 \alpha$-phorbol 12,13-

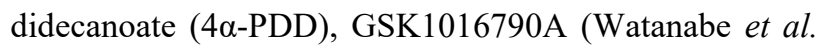
2002a) (Watanabe et al. 2002a, Willette et al. 2008), as well as moderate warmth $\left(>27^{\circ} \mathrm{C}\right)$ (Güler et al. 2002, Watanabe et al. 2002b) and inhibited by HC-067047 (Everaerts et al. 2010). TRPV4 is widely expressed throughout the body, including esophageal (Mihara et al. 2011), gastric (Mihara et al. 2016) and urinary bladder (Everaerts et al. 2010) epithelia as well as skin keratinocytes (Sokabe et al. 2010), hippocampal neurons (Shibasaki et al. 2007) and endothelial cells (Watanabe et al. 2002b), where it contributes to numerous physiological processes, such as regulation of cell volume, vascular tone, vascular permeability, mechanosensation, proliferation, angiogenesis, secretion, apoptosis and cell death (Yao and Garland 2005, Mihara et al. 2011, 2016, Persson 2015).

Recently, downregulation of endothelial TRPV4 was shown to contribute to the impairment of EDH-mediated relaxation in the mesenteric arteries of stroke-prone hypertensive rats (Seki et al. 2017). However, the potential role of endothelial TRPV4 in mediating NO-dependent relaxation in hypertension is rather unknown. Therefore, in the present study, we investigated whether a dysfunctional TRPV4 is underlying any possible impairment of NO-dependent relaxation in the mesenteric artery of spontaneously hypertensive rats (SHRs). 


\section{Material and Methods}

Animals

Ten to twelve-week-old male spontaneously hypertensive rats (SHRs) and age-matched normotensive Wistar-Kyoto (WKY) rats were used in this study. Rats were housed in a controlled environment (12 h light-12 h dark cycle; room temperature, $22-24{ }^{\circ} \mathrm{C} ; 50-60 \%$ relative humidity) and received standard rat rodent chow and water ad libitum. All procedures were performed in accordance with Sultan Qaboos University (SQU) Animal Ethics Committee regulations and SQU Guidelines for Care and Use of Laboratory Animals.

\section{Determination of blood pressure}

Systolic (SBP) and diastolic (DBP) blood pressure was measured non-invasively by tail-cuff plethysmography using BP-2000 Blood Pressure Analysis System $^{\mathrm{TM}}$ (Visitech Systems, USA). First, the selected animals were acclimated to the equipment once per day for two days before actual testing began. Then, the mean of three measurements of blood pressure was recorded.

\section{Vessel preparation and isometric tension recording}

Rats were anesthetized with an intraperitoneal injection of ketamine $(140 \mathrm{mg} / \mathrm{kg})$ and xylazine $(40 \mathrm{mg} / \mathrm{kg})$ mixture. Mesenteric tissues were excised and placed in cold, oxygenated physiological solution containing (in mM) $119 \mathrm{NaCl}, 4.7 \mathrm{KCl}, 1.18 \mathrm{KH}_{2} \mathrm{PO} 4$, $1.17 \mathrm{MgSO}_{4}, 25 \mathrm{NaHCO}_{3}, 5.5$ glucose, 10 HEPES and $1.6 \mathrm{CaCl}_{2}$ (pH 7.4 adjusted with $\mathrm{NaOH}$ ). Second order branches from the mesenteric artery were cleaned of connective and adipose tissues, and cut into segments of $2 \mathrm{~mm}$ length. According to the experimental requirement, the endothelium was either kept intact or removed by gentle rubbing of the lumen with a fine hair. Then arterial rings were threaded on two thin wires $(40 \mu \mathrm{m}$ in diameter) and mounted in a four-chamber wire myograph DMT (Danish Myo Technology A/S, Aarhus, Denmark) containing a physiological solution that was continuously bubbled with a gas mixture of $95 \% \mathrm{O}_{2}$ and $5 \% \mathrm{CO}_{2}$.

After the normalization procedure, arteries were left to equilibrate for $60 \mathrm{~min}$ at $37^{\circ} \mathrm{C}$ before subsequent evaluation. At the end of this period, the tension created by the arterial segments was considered as the resting (basal) tension, and no further mechanical adjustment was made during experimentation. Isometric responses were filtered and recorded using a PowerLab acquisition system and LabChart 8 software (AD Instruments, Bella Vista NSW, Australia).

\section{Experimental protocol}

The resting tension of vessels was measured $60 \mathrm{~min}$ after mounting the vessels at $37^{\circ} \mathrm{C}$. After that, arteries were contracted twice with $60 \mathrm{mM} \mathrm{KCl}$ to test their viability, then $\mathrm{KCl}$ was washed out, and vessels were contracted with $4 \mu \mathrm{M}$ phenylephrine (PE) and then relaxed with $1 \mu \mathrm{M}$ ACh. Segments showing relaxation of more than $80 \%$ for WKY and $50 \%$ for SHR were considered as endothelium-intact (endo+), whereas those with a relaxation of less than $5 \%$, in both strains, were considered as endothelium denuded (endo-) (Bratz et al. 2008). Vessels with relaxation between $5 \%$ and $80 \%$ for WKY and $5 \%$ to $50 \%$ for SHR were excluded. Thereafter, tissues were washed twice to remove PE and ACh. Then the preparations were re-contracted with PE (4 $\mu \mathrm{M})$, and after the contraction reached a steady state, the response to $5 \mu \mathrm{M} 4 \alpha \mathrm{PDD}$ (selective TRPV4 agonist) was determined (Ma et al. 2013). To determine whether the $4 \alpha \mathrm{PDD}$-induced response is mediated by TRPV4 stimulation, the effect of $4 \alpha \mathrm{PDD}$ was examined on arterial preparations pre-incubated for $30 \mathrm{~min}$ with the selective TRPV4 antagonist, HC067047 (1 $\mu \mathrm{M})$ (Everaerts et al. 2010) before being contracted with PE $(4 \mu \mathrm{M})$. Additionally, to explore whether NO is involved in mediating the $4 \alpha \mathrm{PDD}$-induced response, the effect of $4 \alpha$ PDD was studied in preparations pre-incubated with L-NAME $(100 \mu \mathrm{M})$ for $30 \mathrm{~min}$.

The concentrations of the different agonists and antagonists were selected according to previous studies (Hwa et al. 1994, Bubolz et al. 2012, Ma et al. 2013, Albarwani et al. 2015, Zhang et al. 2016, Seki et al. 2017).

\section{Immunostaining}

For section preparation, rats were anesthetized with intraperitoneal injection of ketamine $(140 \mathrm{mg} / \mathrm{kg})$ and xylazine $(40 \mathrm{mg} / \mathrm{kg})$ mixture. Then the thoracic cavity was cut open, and the hearts were perfused by intracardiac infusion of $0.1 \mathrm{M}$ Phosphate-buffered saline (PBS). The small intestines were removed and spread open in dissecting dish containing $4 \%$ paraformaldehyde (PFA). Six second-order mesenteric arterial segments were removed from each rat and fixed in $4 \%$ PFA for 1 hour at $4{ }^{\circ} \mathrm{C}$. PFA-fixed arterial preparations were washed 3 times in $0.1 \mathrm{M}$ PBS (15 minutes each). Then the mesenteric arterial segments were incubated in PBS-sucrose (PBS containing $20 \%$ sucrose) overnight at 
$4{ }^{\circ} \mathrm{C}$. Next day, arteries were embedded in Optimal Cutting Temperature (OCT) compound, and 10- $\mu \mathrm{m}$-thick cross sections were collected onto glass slides, and air dried at room temperature for 1 hour. Four immunostaining, arterial sections were cleared with PBS-T $0.3 \%$ (PBS plus $0.3 \%$ TritonX-100) $(3 \times 5 \mathrm{~min})$. To reduce non-specific antibody binding, tissues were pre-incubated in $10 \%$ hydrogen peroxide $\left(\mathrm{H}_{2} \mathrm{O}_{2}\right.$ in $\left.\mathrm{PBS}\right)$ for 1 hour at room temperature before adding primary antibody. Then preparations were washed 3 times with PBS-T $0.3 \%$ (5 min each).

To study the localization of TRPV4 in the mesenteric artery wall, preparations were incubated with the primary antibody against TRPV4 that was diluted with PBS-T $0.3 \%$ containing $3 \%$ bovine serum albumin (BSA). In order to detect best immunofluorescence signal, serial dilutions of the primary antibody were used in a pilot study as follows: 1:100, 1:200, 1:300, 1:400, $1: 500$ and 1:1000. The dilution of 1:400 was used for the subsequent experiments because it gave the best signal with least background staining. After overnight incubation with primary antibody at $4{ }^{\circ} \mathrm{C}$, preparations were washed 3 times by PBS-T $0.3 \%$ ( 5 min each). Then, the secondary antibody (1:500) was added and incubated for 1 hour at room temperature. After being washed 3 times in PBS-T $0.3 \%$ (5 min each), the sections were stained with 4',6-diamidino-2-phenylindole (DAPI) $(1: 1000)$ for $5 \mathrm{~min}$ to detect the nuclei in the sections. Finally, the slides were mounted using AquaMountant ${ }^{\mathrm{TM}}$. The stained sections were visualized using fluorescence microscopy, and pictures were captured with a camera (Olympus, DP71, Japan).

\section{RNA extraction and Real-Time Polymerase Chain Reaction (RT-PCR)}

Second order mesenteric arteries were quickly isolated from anesthetized rats and put in sterile tubes, and immediately snap frozen in liquid nitrogen. Total RNA was extracted using TRIzol reagent. cDNA was synthesized from $1 \mu \mathrm{g}$ of total RNA using the iScript ${ }^{\mathrm{TM}}$ kit and following the protocol provided by BIO-RAD.

Quantitative Real-time amplifications were performed for TRPV4 and GAPDH by using TaqMan ${ }^{\circledR}$ Fast Advanced Master Mix (Applied Biosystems) detection protocol. They were run in duplicate on 96-well plates using (7500 Fast Real-Time PCR System, Applied Biosystems). The total volume of reactions was $20 \mu \mathrm{l}$ containing: $2 \mu \mathrm{l}$ cDNA template, $1 \mu \mathrm{l}$ primer, $10 \mu \mathrm{l}$ $\operatorname{TaqMan}^{\circledR}$ Fast Advanced Master Mix (Applied
Biosystems) and $7 \mu \mathrm{l}$ RNase/DNase-free sterile water. Negative controls were done in duplicate for each master mix. The RT-PCR reaction started with an initial incubation at $50{ }^{\circ} \mathrm{C}$ for 2 minutes, then a hold for 20 seconds at $95^{\circ} \mathrm{C}$, followed by 40 cycles of amplification with denaturation at $95{ }^{\circ} \mathrm{C}$ for 3 seconds, annealing and extension at $60{ }^{\circ} \mathrm{C}$ for 30 seconds.

\section{Western immunoblotting}

Western immunoblotting was performed according to (Albarwani et al. 2016) with some modification. Briefly, the frozen arteries were thawed and homogenized in RIPA Lysis buffer ( $25 \mathrm{mmol} / \mathrm{l}$ Tris- $\mathrm{HCl}$ [pH 7.6], $150 \mathrm{mmol} / \mathrm{l} \mathrm{NaCl}, 1 \%$ Nonidet P-40, $1 \%$ deoxycholic acid, $0.1 \%$ sodium dodecyl sulfate [SDS]) supplemented with a protease inhibitor cocktail (Roche Applied Science, UK) and centrifuged at $500 \mathrm{~g}$ for $10 \mathrm{~min}$ at $4{ }^{\circ} \mathrm{C}$. The concentration of the extracted protein was measured employing BCA protein assay kit (Thermofisher, UK) using bovine serum albumin as standard. Equal amounts of protein samples $(20 \mu \mathrm{g})$ were loaded, and protein was allowed to be separated in $7.5 \%$ SDS-PAGE gel for one hour. Then, proteins were transferred from the gel onto a nitrocellulose membrane using semi-dry transfer (Trans-Blot Turbo, Bio-Rad, USA) method. The membrane was blocked with $10 \%$ of nonfat dry milk. The protein of interest was detected by probing the membrane with anti-TRPV4 (1:500, Abcam, UK) overnight at $4{ }^{\circ} \mathrm{C}$ or anti-GAPDH (1:5000, ABGENT, USA) for two hours at room temperature. After washing, the membrane was incubated with secondary antibodies, conjugated to horseradish peroxidase (1:5000, Thermo Scientific, UK) for 1 hour at room temperature. Then the membrane was processed for chemiluminescent detection using Super Signal West Dura substrate (Thermo Scientific, UK) using G:Box Chemi XR5 (Syngene, UK). All reactions were performed in duplicate, and GAPDH was used as an internal control.

\section{Drugs and solutions}

Acetylcholine (ACh), phenylephrine (PE), $N_{\omega}$-Nitro-L-arginine methyl ester hydrochloride

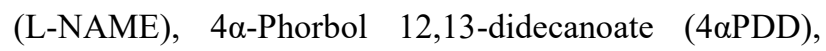
HC067047, $4 \%$ paraformaldehyde, TritonX-100 and $\mathrm{H}_{2} \mathrm{O}_{2}$ were purchased from Sigma Chemicals (Germany). $\mathrm{ACh}, \mathrm{PE}$, and L-NAME solutions were prepared in distilled water. The $4 \alpha \mathrm{PDD}$ solution was reconstituted in absolute ethanol and HC067047 in dimethyl sulfoxide 
(DMSO). Their concentrations as indicated in the text are the final concentrations in the chamber solutions. Final concentrations of the vehicle were less than $0.1 \%$. PBS $(0.1 \mathrm{M})$ was prepared according to the following composition (mM): $\mathrm{NaCl}, 137 ; \mathrm{KCl}, 2.7 ; \mathrm{Na}_{2} \mathrm{HPO}_{4}, 10.1$; $\mathrm{KH}_{2} \mathrm{PO}_{4}, 1.8 ; \mathrm{CaCl}_{2} .2 \mathrm{H}_{2} \mathrm{O}, 0.9 ; \mathrm{MgCl}_{2} .6 \mathrm{H}_{2} \mathrm{O}, 0.5$, and aerated with $95 \% \mathrm{O}_{2}$ and $5 \% \mathrm{CO}_{2}$. Optimal Cutting Temperature compound was purchased from VWR chemicals (UK). DAPI (ab228549), BSA (ab64009), primary (Rabbit polyclonal to TRPV4; ab39260) and secondary antibodies (Goat Anti-Rabbit IgG Alexa Fluor ${ }^{\circledR}$ 594; ab150080) were purchased from Abcam company (UK) and were diluted using PBS. The iScript $^{\mathrm{TM}}$ kit that was used for cDNA synthesis was purchased from Bio-Rad company (USA), and TaqMan ${ }^{\circledR}$ Master Mix was purchased from Applied Biosystems (USA). TaqMan ${ }^{\circledR}$ gene expression assay for TRPV4 and GAPDH were purchased from ThermoFisher Scientific Company (Cat. \# 4331182, Rn00576745_m1 and Cat. \# 4331182, Rn01775763_g1, respectively).

\section{Analysis and statistics}

The PE-induced contraction of arterial rings was expressed as the percentage to the respective resting tension, and the extent of the relaxation response to different agonists was expressed as the percentage reversal of PE-induced contraction (Albarwani et al. 2015). The relative change in gene expression was studied by calculating the fold change (Sukumaran et al. 2013). The immunoblot band densities were analyzed by using ImageJ software (NIH, USA) and the optical density of each sample was normalized to GAPDH of the respective sample.

The collected data were analyzed using SPSS 23.0 and results were expressed as mean \pm S.E.M. with $n$ refers to the number of rats. To determine the level of significance, statistical comparisons were performed using the unpaired (independent) Student's $t$-test and the differences were considered statistically significant when $\mathrm{p}<0.05$.

\section{Results}

\section{Blood pressure of SHR and WKY rats}

As expected, the blood pressure in SHR was significantly higher than WKY rats $(189 \pm 11 / 115 \pm$ $8 \mathrm{mmHg}$ vs. $144 \pm 7 / 83 \pm 5 \mathrm{mmHg} ; \mathrm{n}=5-6 ; P<0.01$ for $\mathrm{SBP}$ and $P<0.05$ for DBP).

\section{Basal tensions and responses to PE}

At the end of the equilibration period, the resting tensions of the SHR mesenteric arteries were slightly higher compared to arteries obtained from WKY rats (both endothelium-intact). However, the difference was not significant $(3.34 \pm 0.46 \mathrm{mN} ; \mathrm{n}=6$ vs. $2.48 \pm 0.32 \mathrm{mN}$; $\mathrm{n}=5 ; P=0.1755)$. Similarly, the PE-induced contractions in SHR were higher, though not significant, in comparison to WKY rats $(326.80 \pm 44.25 \%$ vs. $231.69 \pm 44.99 \% ; n=5-6 ; p=0.1690$ ) (Fig. 1a). Incubation of arteries with L-NAME or HC067047 did not significantly affect the basal tension or PE-induced contractions (data not shown).

A

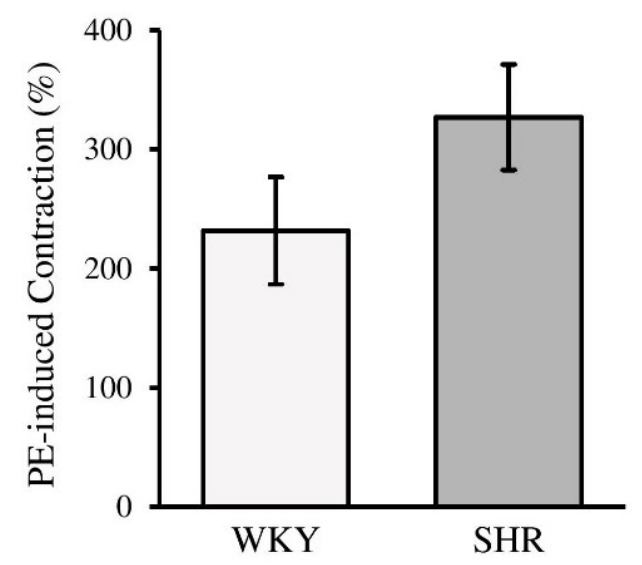

B

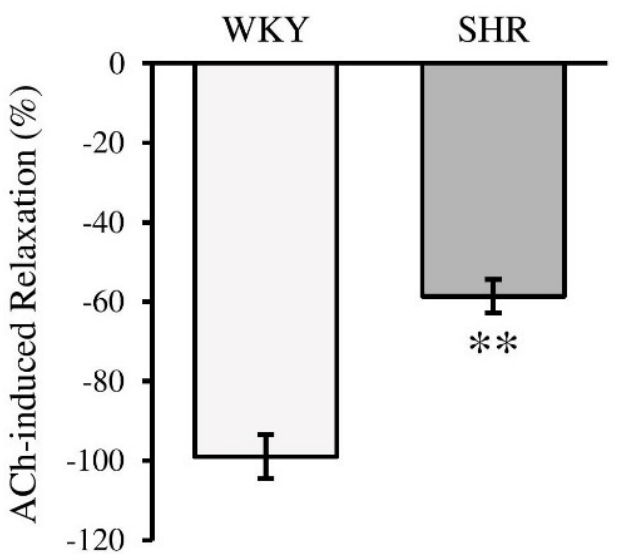

Fig. 1. Phenylephrine (PE)-induced contractions and acetylcholine (ACh)-induced relaxations in mesenteric arteries obtained from Wistar-Kyoto (WKY) rats and spontaneously hypertensive rats (SHRs). (A) PE $4 \mu \mathrm{M}$ evoked contractions that were slightly higher, though not significant, in artery segments from SHR compared to WKY controls. (B) ACh-evoked relaxations were significantly lower in PE-precontracted mesenteric artery segments from SHR compared to WKY controls. $* * p<0.01$ vs. WKY controls $(n=5-6)$. 


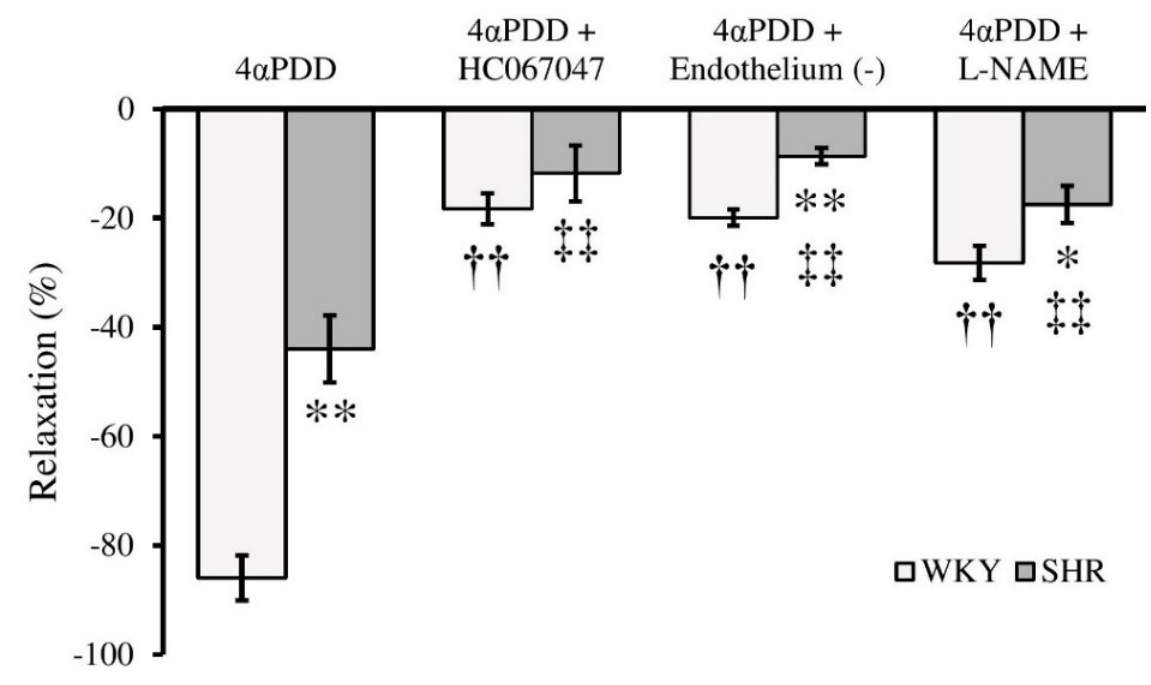

Fig. 2. $4 a P D D$-induced relaxations in mesenteric artery segments obtained from spontaneously hypertensive rats (SHRs) and Wistar-Kyoto (WKY) controls. Artery segments were precontracted with $4 \mu \mathrm{M}$ PE. 4aPDD-induced relaxations were significantly lower in segments from SHR than those from WKY controls. The 4aPDD-induced relaxations were significantly blocked by HC067047, endothelium denudation and L-NAME in both WKY and SHR. $* P<0.05, * * P<0.01$ vs. WKY, ${ }^{++} P<0.01$ vs. WKY control (WKY $4 \mathrm{aPDD})$ and $\neq \neq P<0.01$ vs. SHR control (SHR 4aPDD) $(n=5-6)$.
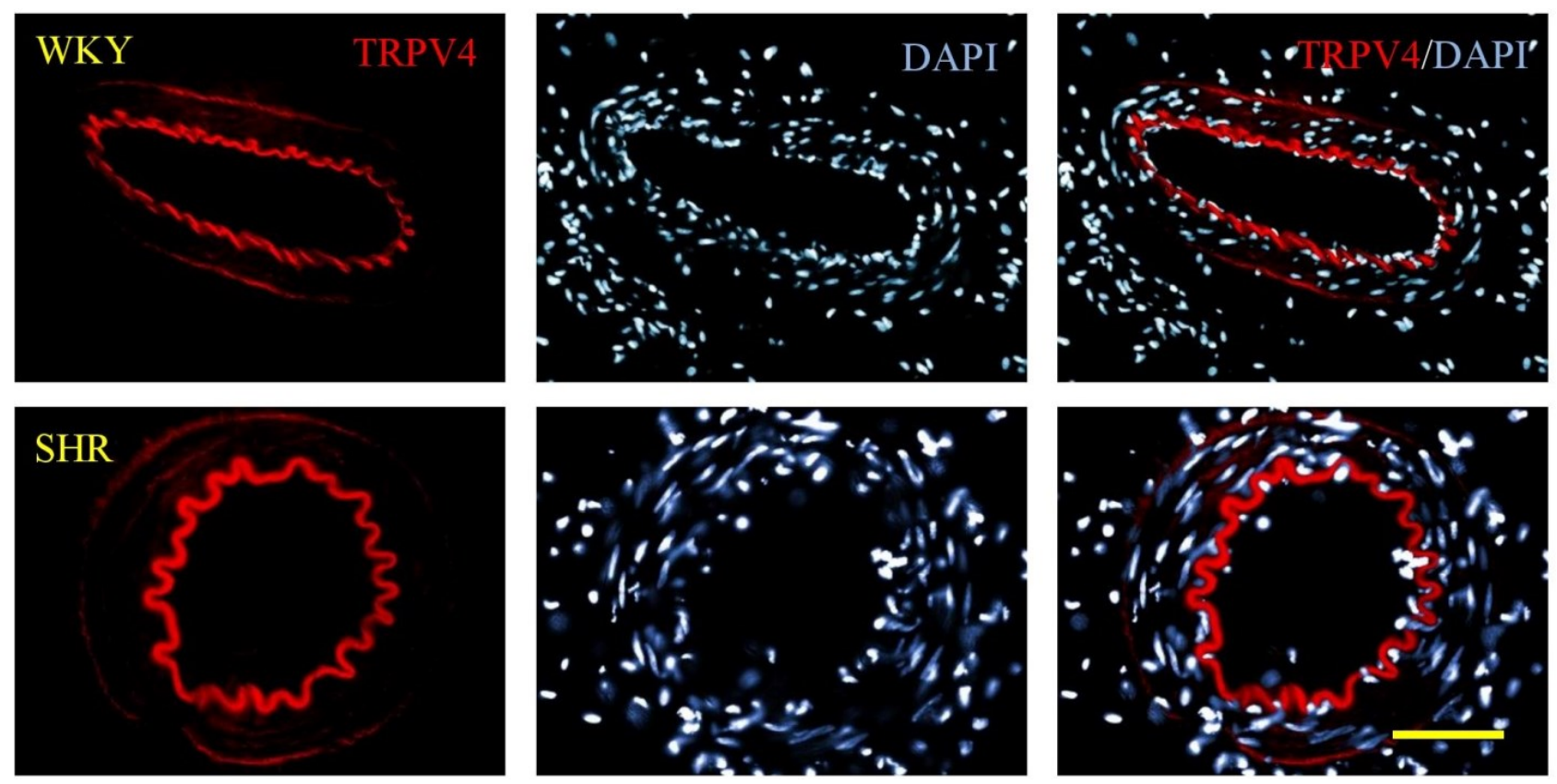

Fig. 3. TRPV4 immunoreactivity in Wistar-Kyoto (WKY) and spontaneously hypertensive rat (SHR) mesenteric artery. TRPV4 immunoreactivity was observed in WKY and SHR mesenteric artery endothelial layers. Scale bar indicates $100 \mu \mathrm{m}$. DAPI: sections were stained with 4',6-diamidino-2-phenylindole; TRPV4/DAPI: both images (with TRPV4 staining and with DAPI staining) were merged.

\section{Endothelium-dependent vasodilation}

The endothelium-dependent relaxation to $\mathrm{ACh}$ $(1 \mu \mathrm{M})$ was significantly lower in mesenteric arteries of SHR compared with those of WKY rats $(58.63 \pm 4.20 \%$; vs. $98.95 \pm 5.53 \% ; \quad n=5-6: \quad P<0.01 \quad$ (Fig. 1b). These ACh-mediated relaxations were abolished by removal of the endothelium in both strains (data not shown).

\section{TRPV4-mediated vasodilation in WKY rats}

Stimulation of arterial rings obtained from WKY rats, pre-contracted with $\mathrm{PE}(4 \mu \mathrm{M})$, using the specific TRPV4 agonist, $4 \alpha$ PDD $(5 \mu \mathrm{M})$, induced a relaxation response that was significantly inhibited by the selective TRPV4 antagonist HC067047 $(1 \mu \mathrm{M})(85.98 \pm 4.18 \%$ vs. $18.30 \pm 2.86 \% ; \mathrm{n}=5, P<0.01$ ) (Fig. 2). To determine whether the TRPV4-induced relaxation is endotheliumdependent and mediated by endothelial NO, we next studied the effect of endothelium removal and L-NAME (100 $\mu \mathrm{M})$, separately, on TRPV4-induced relaxation response in the mesenteric artery. As shown in Figure 2, there was a significant impairment of the TRPV4-induced relaxation in both endothelium-denuded (19.93 $\pm 1.50 \%$; $\mathrm{n}=5, \quad P<0.01)$ and L-NAME-treated vessels $(28.18 \pm$ $3.09 \%$; $=5, P<0.01$ ) (Fig. 2). 
TRPV4-mediated response in SHR compared to WKY rats In order to compare the functional expression of TRPV4 in SHR and WKY rats, relaxation responses to $4 \alpha$ PDD $(5 \mu \mathrm{M})$ in SHR were compared to those in WKY rats. As shown in Figure 2, the TRPV4-mediated relaxation was significantly lower in SHR compared to WKY rats $(85.98 \pm 4.18 \%$ vs. $43.99 \pm 6.12 \%$; $n=5-6$; $P<0.01)$. This significantly lower TRPV4-mediated relaxation was significantly reduced by HC067047 $(1 \mu \mathrm{M}) \quad(11.76 \pm 4.18 \% ; \quad \mathrm{n}=6 ; \quad P<0.01), \quad$ endothelium denudation $(8.64 \pm 1.50 \% ; \mathrm{n}=6 ; P<0.01)$ and L-NAME $(100 \mu \mathrm{M})(17.50 \pm 3.40 \% ; \mathrm{n}=6 ; P<0.01)$ (Fig. 2).

Expression of TRPV4 in the mesenteric arteries of SHR and WKY rats

Using immunohistochemical analysis, a positive immunofluorescence signal was visualized for TRPV4 protein in the endothelial layer of mesenteric arteries obtained from both WKY and SHR strains (Fig. 3). To exclude the possibility of a pseudo-positive reaction for the fluorescence signal, a blank control test without TRPV4 antibody was performed and a negative result was confirmed (data not shown). A weak background staining was found in the underlying smooth muscle cells of mesenteric arteries from all four groups similar to the staining found in the negative control test. Nuclei were stained using DAPI to show the outline of the blood vessel wall (Fig. 3).

Relative expression of TRPV4 $m R N A$ and protein in the mesenteric arteries of SHR and WKY rats

Real-time PCR study was done to assess the level of TRPV4 expression in the mesenteric artery of WKY and SHR strains. TRPV4 mRNA expression was significantly lower in SHR compared to WKY rats $\quad(0.67 \pm 0.34$ RU vs. $2.34 \pm 0.15 \quad \mathrm{RU} ; \mathrm{n}=5$; $P<0.05)$ (Fig. 4A). Western immunoblotting revealed a significantly lower TRPV4 protein expression in SHR mesenteric arteries compared to WKY rats $(0.312 \pm 0.065$ RU vs. $0.821 \pm 0.079$ RU; $\mathrm{n}=5 ; P<0.05$ ) (Fig. 4B).

\section{Discussion}

The main findings of the present study are as follows: (1) activation of TRPV4 with the specific agonist, $4 \alpha \mathrm{PDD}$, induced an endothelium-dependent relaxation of second-order mesenteric arterial rings precontracted with PE and this $4 \alpha \mathrm{PDD}$-induced relaxation was markedly inhibited by blockade of TRPV4 channels

\section{A. RT-PCR}

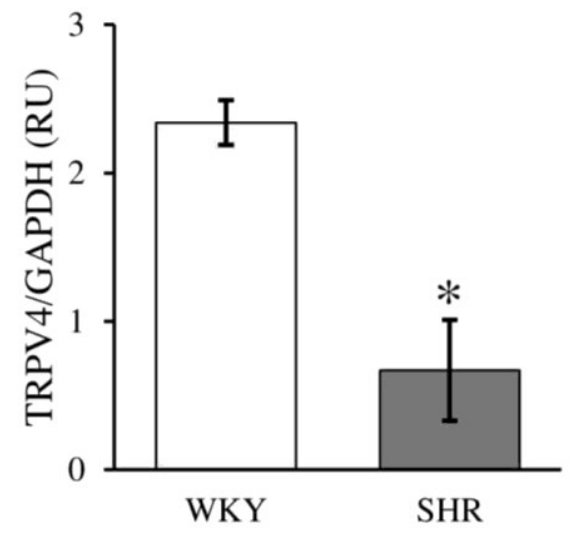

\section{B. Western Blot}

\section{WKY SHR}
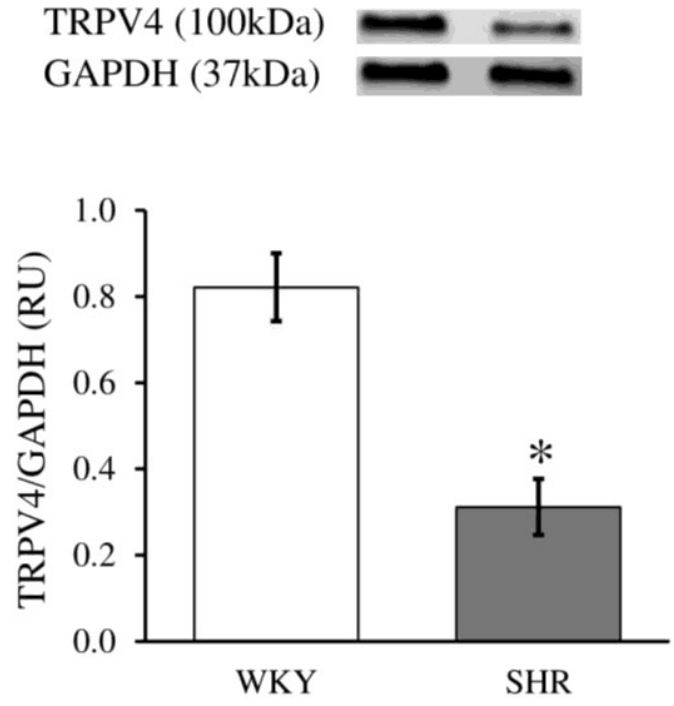

Fig. 4. Relative expression of TRPV4 mRNA (A) and protein (B) in endothelium-intact mesenteric arteries of Wistar-Kyoto (WKY) rats and, spontaneously hypertensive rats (SHRs). Data were shown as mean \pm S.E.M. in relative units (RU) after normalization to GADPH. $* P<0.05$ vs. WKY $(\mathrm{n}=5)$.

by a selective antagonist HC067047, denudation of the endothelium and by the NOS inhibitor, L-NAME; (2) the TRPV4-mediated relaxation was significantly lower in SHR compared to WKY rats; (3) TRPV4 channels were predominantly expressed in the endothelial layer of small mesenteric arteries obtained from WKY and SHR rats, (4) expression of TRPV4 mRNA and protein were significantly lower in SHR compared to WKY rats.

In agreement with the results of previous studies, $\mathrm{ACh}$ induced a relaxation response in rat mesenteric 
arterial ring preparations that was almost completely abolished by endothelium denudation (Lacy et al. 2000, Chen and Qian 2015). The relaxation response to ACh was significantly lower in the mesenteric resistance arteries of SHR compared to WKY rats, which is consistent with previous studies (Tesfamariam and Halpern 1988, Fujii et al. 1992, Bennett et al. 1996, Shimokawa et al. 1996, Goto et al. 2004, Seki et al. 2017).

Stimulation of the pre-contracted mesenteric artery preparations with the selective TRPV4 agonist, $4 \alpha \mathrm{PDD}$, induced a relaxation response that was markedly inhibited by the selective TRPV4 antagonist, HC067047, confirming that the observed $4 \alpha \mathrm{PDD}$-induced relaxation response is mainly due to stimulation of TRPV4 and is consistent with results from previous studies on rat (Ma et al. 2013, Zhang et al. 2016) and mouse mesenteric arteries (Zhang et al. 2009, Mendoza et al. 2010). These results are further supported by Mendoza's group who demonstrated that GSK1016790A, another TRPV4 agonist, induced a relaxation response in mouse mesenteric artery which was absent in TRPV4-knockout (TRPV4 ${ }^{-/}$) mice. Moreover, the flow-mediated dilation and vessel relaxation detected in mesenteric arteries of wild-type mice were significantly reduced in TRPV4 ${ }^{-/-}$ mice (Mendoza et al. 2010).

Our data also reveal that $4 \alpha \mathrm{PDD}$-induced relaxation is primarily endothelium-dependent since denudation of the endothelium significantly inhibited this relaxation, confirming that the response requires an intact endothelium. This is supported by previous findings where $4 \alpha \mathrm{PDD}$ failed to induce cationic current in endothelial cells of TRPV4 ${ }^{-/}$mice carotid artery (Hartmannsgruber et al. 2007) and was able to induce a relaxation response in endothelium-intact, but not in endothelium-denuded rat and mouse mesenteric arteries (Zhang et al. 2009, 2016, Mendoza et al. 2010), while endothelium-independent relaxations in both, wild-type and TRPV4 ${ }^{-/}$mice, were nearly the same (Mendoza et al. 2010). The observed $4 \alpha \mathrm{PDD}$-induced relaxation in endothelium-denuded preparations of both strains could be due to the activation of vascular smooth muscle TRPV4 (Yang et al. 2006, Earley et al. 2009, Gao and Wang 2010, Baylie and Brayden 2011), and the significantly lower response seen in SHR could be attributable to the alteration in the function and expression of the smooth muscle TRPV4 in this strain compared to WKY rats.

To explain the observed significant dependence of $4 \alpha$ PDD-induced relaxation on stimulation of endothelial TRPV4 channels, immunohistochemical analysis was employed and it revealed that TRPV4 channels are mainly expressed on the endothelium of mesenteric arteries in both WKY and SHR, and in agreement with previous studies on mouse mesenteric and aortic arteries (Zhang et al. 2009, Mendoza et al. 2010), and rat mesenteric, pulmonary and carotid arteries (Loot et al. 2008, Willette et al. 2008, Sukumaran et al. 2013, Peixoto-Neves et al. 2015). Furthermore, the immunofluorescent signal for TRPV4 protein that was seen in the endothelial cells of wild-type mesenteric and carotid arteries was not seen in those of TRPV4 ${ }^{-/-}$mice (Hartmannsgruber et al. 2007, Mendoza et al. 2010). Sukumaran's group measured the relative mRNA and protein expression of TRPV4 in endothelium-intact and endothelium-denuded pulmonary artery, and they reported that mRNA and protein expression of TRPV4 in endothelium-intact were significantly higher than in endothelium-denuded (Sukumaran et al. 2013), which provide further evidence for the predominance of endothelial expression of TRPV4.

To explore whether stimulation of TRPV4 by $4 \alpha$ PDD will release NO to mediate the endotheliumdependent relaxation response, we blocked the enzyme nitric oxide synthase by L-NAME. After an incubation period with L-NAME for $30 \mathrm{~min}$, $4 \alpha \mathrm{PDD}$-induced relaxation was significantly inhibited in mesenteric arteries precontracted with $\mathrm{PE}$ indicating that $\mathrm{NO}$ is involved in mediating $4 \alpha \mathrm{PDD}$-induced relaxation. Therefore, NO seems to be a major mediator of TRPV4-relaxing effect in the current study. Stimulation of TRPV4 by $4 \alpha \mathrm{PDD}$ may, therefore, increases endothelial $\left[\mathrm{Ca}^{+2}\right]$, which in turn stimulates the enzyme nitric oxide synthase that is crucial for NO synthesis in endothelial cells (Félétou and Vanhoutte 2006, Loh et al. 2018).

The amplitude of relaxation induced by TRPV4 stimulation in SHR was significantly lower when compared to WKY. Our data clearly illustrate the existence of a difference in the functional expression of TRPV4 between WKY and SHR. Recently, and in agreement with our results, Seki's group showed that GSK1016790A (TRPV4 agonist) induced a TRPV4mediated relaxation response in mesenteric arterial rings obtained from WKY rats and this response was markedly impaired in stroke-prone spontaneously hypertensive rats (SHRSPs). However, they attributed the TRPV4-induced relaxation to be mainly mediated by the activation of 
endothelial $\mathrm{IK}_{\mathrm{Ca}} \& \mathrm{SK}_{\mathrm{Ca}}$ with minimal or no role of $\mathrm{NO}$, which is dissimilar to our results (Seki et al. 2017). The reason for this disagreement is not apparent. However, several reasons might be behind this difference. For instance, the strain of rat (SHRSP), the age (20 weeks) or the size of the mesenteric artery (main branch of the superior mesenteric artery) they used. Simonsen's group had shown that endothelium-dependent relaxation of the rat superior mesenteric artery is directly correlated to the endogenous release of NO (Simonsen et al. 1999). Further, it was shown that the relative importance of NO and EDHF in endothelium-dependent relaxation in rat mesenteric vascular bed is dependent on vessel size where NO is a major player in proximal larger mesenteric artery, whereas EDHF plays a more important role in the relaxation of smaller more distal branches (Hwa et al. 1994, Tomioka et al. 1999, Hilgers et al. 2006). Nitric oxide synthase inhibition with L-NAME was shown to attenuate EDHF-mediated relaxation induced by GSK1016790A (TRPV4 agonist) in rat pulmonary artery (Addison et al. 2016). This could provide an explanation for the apparent discrepancy between our findings and Seki's group results; i.e., lower level of NO produced by the endothelium will lead to less EDHF-mediated relaxation (Seki et al. 2017). Seki's group had also shown that the impaired EDH-mediated responses in the superior mesenteric arteries of SHRSP are attributable to downregulation of TRPV4 and $\mathrm{SK}_{\mathrm{Ca}}$ channels (Seki et al. 2017). $\mathrm{SK}_{\mathrm{Ca}}$ deficient mice exhibited impaired NO-mediated dilatation to $\mathrm{ACh}$ and shear stress stimulation (Brähler et al. 2009, Kerr et al. 2012). Taking all the aforementioned explanations together, the interplay between NO- and EDH-dependent vasorelaxing mechanisms is well established, and it provides further explanation of our results in light of Seki's group findings.

To find out whether the decrease in the amplitude of $4 \alpha \mathrm{PDD}$-induced relaxation in SHR was due to downregulation or dysfunction of TRPV4 that is expressed on the endothelium, we performed RT-PCR. This later showed significantly lower level of TRPV4 mRNA expression in the mesenteric artery of SHR compared to its expression level in the WKY. These results were in correlation with the immunoblotting results, where TRPV4 protein expression was shown to be significantly lower in SHR mesenteric arteries compared to WKY rats, and clearly explain the significantly lower relaxation response to $4 \alpha \mathrm{PDD}$ observed in SHR compared to WKY. Our data agree with the recent study where TRPV4 was shown to be downregulated in mesenteric arteries of SHRSPs (Seki et al. 2017).

In conclusion, our results suggest that TRPV4 is expressed primarily in the endothelium of rat mesenteric artery and its activation causes endothelium-dependent relaxation mediated by NO. Downregulation of TRPV4 causes attenuation of this endothelium-dependent NO-mediated vasorelaxation in hypertensive rats. Impairment of TRPV4 functional activity, as part of endothelium dysfunction, will represent a target for novel pharmacological or gene-based treatment of human hypertension.

\section{Conflict of Interest}

The authors declare that there is no conflict of interest associated with this study.

\section{Acknowledgements}

The authors are thankful to prof. Sulayma Al-Barwani for providing the wire myograph to complete this research. The authors wish to acknowledge the staff of the Small Animal House for their technical support in handling the experimental rats, and we are grateful to Shadia Al-Sinawi and Hamida Al-Barwani for their technical support with immunohistochemistry and RT-PCR. The study was supported by SQU grant to A. Boudaka.

\section{References}

ADDISON MP, SINGH TU, PARIDA S, CHOUDHURY S, KASA JK, SUKUMARAN SV, DARZI SA, KANDASAMY K, SINGH V, KUMAR D, MISHRA SK: NO synthase inhibition attenuates EDHF-mediated relaxation induced by TRPV4 channel agonist GSK1016790A in the rat pulmonary artery: Role of TxA2. Pharmacol Rep 68: 620-626, 2016.

ALBARWANI S, AL-SIYABI S, AL-HUSSEINI I, AL-ISMAIL A, AL-LAWATI I, AL-BAHRANI I, TANIRA MO: Lisinopril alters contribution of nitric oxide and $\mathrm{KCa}$ channels to vasodilatation in small mesenteric arteries of spontaneously hypertensive rats. Physiol Res 64: 39-49, 2015. 
ALBARWANI SA, MANSOUR F, KHAN AA, AL-LAWATI I, AL-KAABI A, AL-BUSAIDI AM, AL-HADHRAMI S, AL-HUSSEINI I, AL-SIYABI S, TANIRA MO: Aging reduces L-type calcium channel current and the vasodilatory response of small mesenteric arteries to calcium channel blockers. Front Physiol 7: 1-8, 2016.

BAYLIE RL, BRAYDEN JE: TRPV channels and vascular function. Acta Physiol 203: 99-116, 2011.

BENNETT MA, HILLIER C, THURSTON H: Endothelium-dependent relaxation in resistance arteries from spontaneously hypertensive rats: Effect of long-term treatment with perindopril, quinapril, hydralazine or amlodipine. J Hypertens 14: 389-397, 1996.

BRÄHLER S, KAISTHA A, SCHMIDT VJ, WÖLFLE SE, BUSCH C, KAISTHA BP, KACIK M, HASENAU AL, GRGIC I, SI H, BOND CT, ADELMAN JP, WULFF H, DE WIT C, HOYER J, KÖHLER R: Genetic deficit of SK3 and IK1 channels disrupts the endothelium-deerived hyperpolarizing factor vasodilator pathway and causes hypertension. Circulation 119: 2323-2332, 2009.

BRATZ IN, DICK GM, TUNE JD, EDWARDS JM, NEEB ZP, DINCER UD, STUREK M: Impaired capsaicin-induced relaxation of coronary arteries in a porcine model of the metabolic syndrome. Am J Physiol Circ Physiol 294: H2489-H2496, 2008.

BUBOLZ AH, MENDOZA SA, ZHENG X, ZINKEVICH NS, LI R, GUTTERMAN DD, ZHANG DX: Activation of endothelial TRPV4 channels mediates flow-induced dilation in human coronary arterioles: role of $\mathrm{Ca}^{2+}$ entry and mitochondrial ROS signaling. Am J Physiol Heart Circ Physiol 302: H634-H642, 2012.

CHEN XP, QIAN LR: The vasodilatory action of telmisartan on isolated mesenteric artery rings from rats. Iran J Basic Med Sci 18: 974-978, 2015.

DAL-ROS S, BRONNER C, SCHOTT C, KANE MO, CHATAIGNEAU M, SCHINI-KERTH VB, CHATAIGNEAU T: Angiotensin II-induced hypertension is associated with a selective inhibition of endothelium-derived hyperpolarizing factor-mediated responses in the rat mesenteric artery. J Pharmacol Exp Ther 328: 478-486, 2009.

EARLEY S, PAUYO T, DRAPP R, TAVARES MJ, LIEDTKE W, BRAYDEN JE: TRPV4-dependent dilation of peripheral resistance arteries influences arterial pressure. Am J Physiol Heart Circ Physiol 297: H1096-H1 102, 2009.

EDWARDS G, FÉLÉTOU M, WESTON AH: Endothelium-derived hyperpolarising factors and associated pathways: A synopsis. Pflugers Arch Eur J Physiol 459: 863-879, 2010.

EVERAERTS W, ZHEN X, GHOSH D, VRIENS J, GEVAERT T, GILBERT JP, HAYWARD NJ, MCNAMARA CR, XUE F, MORAN MM, STRASSMAIER T, UYKAL E, OWSIANIK G, VENNEKENS R, DE RIDDER D, NILIUS B, FANGER CM, VOETS T: Inhibition of the cation channel TRPV4 improves bladder function in mice and rats with cyclophosphamide-induced cystitis. Proc Natl Acad Sci 107: 19084-19089, 2010.

FÉLÉTOU M, VANHOUTTE PM: Endothelium-derived hyperpolarizing factor: Where are we now? Arterioscler Thromb Vasc Biol 26: 1215-1225, 2006.

FILOSA JA, YAO X, RATH G: TRPV4 and the regulation of vascular tone. J Cardiovasc Pharmacol 61: 113-119, 2013.

FUJII K, TOMINAGA M, OHMORI S, KOBAYASHI K, KOGA T, TAKATA Y, FUJISHIMA M: Decreased endothelium-dependent hyperpolarization to acetylcholine in smooth muscle of the mesenteric artery of spontaneously hypertensive rats. Circ Res 70: 660-669, 1992.

GAO F, WANG DH: Impairment in Function and Expression of TRPV4 in Dahl Salt-Sensitive Rats: Significance and Mechanism. Hypertension 55: 1018-1025, 2010.

GILES TD, SANDER GE, NOSSAMAN BD, KADOWITZ PJ: Impaired Vasodilation in the Pathogenesis of Hypertension: Focus on Nitric Oxide, Endothelial-Derived Hyperpolarizing Factors, and Prostaglandins. J Clin Hypertens 14: 198-205, 2012.

GOTO K, FUJII K, KANSUI Y, IIDA M: Changes in endothelium-derived hyperpolarizing factor in hypertension and ageing: response to chronic treatment with renin-angiotensin system inhibitors. Clinical and Experimental Pharmacology and Physiology 31: 650-655. 2004.

GOTO K, OHTSUBO T, KITAZONO T: Endothelium-dependent hyperpolarization (EDH) in hypertension: The role of endothelial ion channels. Int J Mol Sci 19: 2018. pii: E315. doi: 10.3390/ijms19010315. 
GÜLER AD, LEE H, IIDA T, SHIMIZU I, TOMINAGA M, CATERINA M: Heat-Evoked Activation of the Ion Channel, TRPV4. J Neurosci 22: 6408-6414, 2002.

HALL JE, GRANGER JP, HALL ME: Physiology and Pathophysiology of Hypertension. In: Seldin and Geibisch's The Kidney. ALPERN RJ, CAPLAN MJ, MOE OW (eds), Elsevier, 2013, pp 1319-1352.

HARTMANNSGRUBER V, HEYKEN WT, KACIK M, KAISTHA A, GRGIC I, HARTENECK C, LIEDTKE W, HOYER J, KÖHLER R: Arterial response to shear stress critically depends on endothelial TRPV4 expression. PLoS One 2: e827, 2007.

HAYAKAWA H, RAIJ L: Nitric Oxide Synthase Activity and Renal Injury in Genetic Hypertension. Hypertension 31: 266-270, 1998.

HILGERS RHP, TODD J, WEBB RC: Regional heterogeneity in acetylcholine-induced relaxation in rat vascular bed: role of calcium-activated K+ channels. Am J Physiol Heart Circ Physiol 291: H216-H222, 2006.

HILGERS RHP, WEBB RC: Reduced expression of SK $\mathrm{Ca}_{\text {and }}$ IK $\mathrm{Ca}_{\text {can }}$ channel proteins in rat small mesenteric arteries during angiotensin II-induced hypertension. Am J Physiol Heart Circ Physiol 292: H2275-H2284, 2007.

HILL CE, PHILLIPS JK, SANDOW SL: Heterogeneous control of blood flow amongst different vascular beds. Med Res Rev 21: 1-60, 2001.

HWA JJ, GHIBAUDI L, WILLIAMS P, CHATTERJEE M: Comparison of acetylcholine-dependent relaxation in large and small arteries of rat mesenteric vascular bed. Am J Physiol Circ Physiol 266: H952-H958, 1994.

KANETO H, KATAKAMI N, MATSUHISA M, MATSUOKA T: Role of Reactive Oxygen Species in the Progression of Type 2 Diabetes and Atherosclerosis. Mediators Inflamm 2010: 1-11, 2010.

KANG KT: Endothelium-derived relaxing factors of small resistance arteries in hypertension. Toxicol Res 30: 141-148, 2014.

KERR PM, TAM R, NARANG D, POTTS K, MCMILLAN D, MCMILLAN K, PLANE F: Endothelial calciumactivated potassium channels as therapeutic targets to enhance availability of nitric oxide. Can J Physiol Pharmacol 90: 739-752, 2012.

LACY PS, PILKINGTON G, HANVESAKUL R, FISH HJ, BOYLE JP, THURSTON H: Evidence against potassium as an endothelium-derived hyperpolarizing factor in rat mesenteric small arteries. Br J Pharmacol 129: 605-611, 2000.

LANDMESSER U, DIKALOV S, PRICE SR, MCCANN L, FUKAI T, HOLLAND SM, MITCH WE, HARRISON DG: Oxidation of tetrahydrobiopterin leads to uncoupling of endothelial cell nitric oxide synthase in hypertension. J Clin Invest 111: 1201-1209, 2003.

LIEDTKE W, CHOE Y, MARTÍ-RENOM MA, BELL AM, DENIS CS, ANDREJŠALI, HUDSPETH AJ, FRIEDMAN JM, HELLER S: Vanilloid receptor-related osmotically activated channel (VR-OAC), a candidate vertebrate osmoreceptor. Cell 103: 525-535, 2000.

LOH YC, TAN CS, CH'NG YS, YEAP ZQ, NG CH, YAM MF: Overview of the microenvironment of vasculature in vascular tone regulation. Int J Mol Sci 19 In press 2018. pii: E120. doi: 10.3390/ijms19010120

LOOT AE, POPP R, FISSLTHALER B, VRIENS J, NILIUS B, FLEMING I: Role of cytochrome P450-dependent transient receptor potential V4 activation in flow-induced vasodilatation. Cardiovasc Res 80: 445-452, 2008.

MA X, DU J, ZHANG P, DENG J, LIU J, LAM FFY, LI RA, HUANG Y, JIN J, YAO X: Functional role of TRPV4KCa2.3 signaling in vascular endothelial cells in Normal and streptozotocin-induced diabetic rats. Hypertension 62: 134-139, 2013.

MAYET J, HUGHES A: Cardiac and vascular pathophysiology in hypertension. Heart 89: 1104-1109, 2003.

MENDOZA SA, FANG J, GUTTERMAN DD, WILCOX DA, BUBOLZ AH, LI R, SUZUKI M, ZHANG DX: TRPV4mediated endothelial Ca2+ influx and vasodilation in response to shear stress. AJP Hear Circ Physiol 298: H466-H476, 2010.

MIHARA H, BOUDAKA A, SUGIYAMA T, MORIYAMA Y, TOMINAGA M: Transient receptor potential vanilloid 4 (TRPV4)-dependent calcium influx and ATP release in mouse oesophageal keratinocytes. $J$ Physiol 589: 3471-3482, 2011.

MIHARA H, SUZUKI N, BOUDAKA AA, MUHAMMAD JS, TOMINAGA M, TABUCHI Y, SUGIYAMA T: Transient receptor potential vanilloid 4-dependent calcium influx and ATP release in mouse and rat gastric epithelia. World J Gastroenterol 22: 5512-5519, 2016. 
NISHIJIMA Y, ZHENG X, LUND H, SUZUKI M, MATTSON DL, ZHANG DX: Characterization of blood pressure and endothelial function in TRPV4-deficient mice with L-NAME- and angiotensin II-induced hypertension. Physiol Rep 2: e00199, 2014.

PEIXOTO-NEVES D, WANG Q, LEAL-CARDOSO JH, ROSSONI L V., JAGGAR JH: Eugenol dilates mesenteric arteries and reduces systemic BP by activating endothelial cell TRPV4 channels. Br J Pharmacol 172: 3484-3494, 2015.

PERSSON PB: TRPs revisited. Acta Physiol 214: 6-7, 2015.

QUILLON A, FROMY B, DEBRET R: Endothelium microenvironment sensing leading to nitric oxide mediated vasodilation: A review of nervous and biomechanical signals. Nitric Oxide 45: 20-26, 2015.

SEKI T, GOTO K, KIYOHARA K, KANSUI Y, MURAKAMI N, HAGA Y, OHTSUBO T, MATSUMURA K, KITAZONO T: Downregulation of Endothelial Transient Receptor Potential Vanilloid Type 4 Channel and Small-Conductance of $\mathrm{Ca}^{2+}$-Activated $\mathrm{K}^{+}$Channels Underpins Impaired Endothelium-Dependent Hyperpolarization in Hypertension. Hypertension 69: 143-153, 2017.

SHIBASAKI K, SUZUKI M, MIZUNO A, TOMINAGA M: Effects of Body Temperature on Neural Activity in the Hippocampus: Regulation of Resting Membrane Potentials by Transient Receptor Potential Vanilloid 4. J Neurosci 27: 1566-1575, 2007.

SHIMOKAWA H, YASUTAKE H, FUJI K, OWADA MK, NAKAIKE R, FUKUMOTO Y, TAKAYANAGI T, NAGAO T, EGASHIRA K, FUJISHIMA M, TAKESHITA A: The importance of the hyperpolarizing mechanism increases as the vessel size decreases in endothelium-dependent relaxations in rat mesenteric circulation. J Cardiovasc Pharmacol 28: 703-711, 1996.

SIMONSEN U, WADSWORTH RM, BUUS NH, MULVANY MJ: In vitro simultaneous measurements of relaxation and nitric oxide concentration in rat superior mesenteric artery. J Physiol 516: 271-282, 1999.

SOKABE T, FUKUMI-TOMINAGA T, YONEMURA S, MIZUNO A, TOMINAGA M: The TRPV4 channel contributes to intercellular junction formation in keratinocytes. J Biol Chem 285: 18749-18758, 2010.

STROTMANN R, HARTENECK C, NUNNENMACHER K, SCHULTZ G, PLANT TD: OTRPC4, a nonselective cation channel that confers sensitivity to extracellular osmolarity. Nat Cell Biol 2: 695-702, 2000.

SUKUMARAN S V., SINGH TU, PARIDA S, NARASIMHA REDDY CE, THANGAMALAI R, KANDASAMY K, SINGH V, MISHRA SK: TRPV4 channel activation leads to endothelium-dependent relaxation mediated by nitric oxide and endothelium-derived hyperpolarizing factor in rat pulmonary artery. Pharmacol Res 78: 18-27, 2013.

TESFAMARIAM B, HALPERN W: Endothelium-dependent and endothelium-independent vasodilation in resistance arteries from hypertensive rats. Hypertension 11: 440-444, 1988.

THOMAS GR, WALDER CE, THIEMERMANN C, VANE JR: Regional vascular resistance and haemodynamics in the spontaneously hypertensive rat: The effects of bradykinin. J Cardiovasc Pharmacol 15: 211-217, 1990.

TOBIA AJ, WALSH GM, LEE JY: Hemodynamic Alterations in the Young Spontaneously Hypertensive Rat: Elevated Total Systemic and Hindquarter Vascular Resistance. Exp Biol Med 146: 670-673, 1974.

TOMIOKA H, HATTORI Y, FUKAO M, SATO A, LIU MY, SAKUMA I, KITABATAKE A, KANNO M: Relaxation in different-sized rat blood vessels mediated by endothelium- derived hyperpolarizing factor: Importance of processes mediating precontractions. J Vasc Res 36: 311-320, 1999.

WATANABE H, DAVIS JB, SMART D, JERMAN JC, SMITH GD, HAYES P, VRIENS J, CAIRNS W, WISSENBACH U, PRENEN J, FLOCKERZI V, DROOGMANS G, BENHAM CD, NILIUS B: Activation of TRPV4 channels (hVRL-2/mTRP12) by phorbol derivatives. J Biol Chem 277: 13569-13577, 2002a.

WATANABE H, VRIENS J, SUH SH, BENHAM CD, DROOGMANS G, NILIUS B: Heat-evoked activation of TRPV4 channels in a HEK293 cell expression system and in native mouse aorta endothelial cells. J Biol Chem 277: 47044-47051, 2002b.

WESTON AH, PORTER EL, HARNO E, EDWARDS G: Impairment of endothelial SK Ca channels and of downstream hyperpolarizing pathways in mesenteric arteries from spontaneously hypertensive rats. $\mathrm{Br} J$ Pharmacol 160: 836-843, 2010. 
WILLETTE RN, BAO W, NERURKAR S, YUE TL, DOE CP, STANKUS G, TURNER GH, JU H, THOMAS H, FISHMAN CE, SULPIZIO A, BEHM DJ, HOFFMAN S, LIN Z, LOZINSKAYA I, CASILLAS LN, LIN M, TROUT REL, VOTTA BJ, THORNELOE K, LASHINGER ES, FIGUEROA DJ, MARQUIS R, XU X: Systemic Activation of the Transient Receptor Potential Vanilloid Subtype 4 Channel Causes Endothelial Failure and Circulatory Collapse: Part 2. J Pharmacol Exp Ther 326: 443-452, 2008.

YANG X-R, LIN M-J, MCINTOSH LS, SHAM JSK: Functional expression of transient receptor potential melastatinand vanilloid-related channels in pulmonary arterial and aortic smooth muscle. Am J Physiol Cell Mol Physiol 290: L1267-L1276, 2006.

YANG Z, KAYE DM: Endothelial Dysfunction and Impaired 1-arginine Transport in Hypertension and Genetically Predisposed Normotensive Subjects. Trends Cardiovasc Med 16: 118-124, 2006.

YAO X, GARLAND CJ: Recent developments in vascular endothelial cell transient receptor potential channels. Circ Res 97: 853-863, 2005.

ZHANG DX, MENDOZA SA, BUBOLZ AH, MIZUNO A, GE ZD, LI R, WARLTIER DC, SUZUKI M, GUTTERMAN DD: Transient receptor potential vanilloid type 4-deficient mice exhibit impaired endotheliumdependent relaxation induced by acetylcholine in vitro and in vivo. Hypertension 53: 532-538, 2009.

ZHANG P, MAO AQ, SUN CY, ZHANG XD, PAN QX, YANG DT, JIN J, TANG CL, YANG ZY, YAO XQ, LU XJ, MA X: Translocation of PKG1 $\alpha$ acts on TRPV4-C1 heteromeric channels to inhibit endothelial $\mathrm{Ca}^{2+}$ entry. Acta Pharmacol Sin 37: 1199-1207, 2016. 